\title{
Multi-Level Surgery in Obstructive Sleep Apnea [OSA]
}

\author{
Hörmann K. MD, Baisch A. MD \\ University Hospital Mannheim \\ Department of Otolaryngology, Head and Neck Surgery \\ D-68135 Mannheim, Germany
}

\begin{abstract}
Obstructive sleep apnea (OSA) is characterized by nocturnal collapsing of the upper airways. Consequently complete cessation of breathing or reduced breathing phases appears. OSA is a widespread disorder affecting up to $11 \%$ of the male and up to $6 \%$ of the female population. It is associated with serious consequences such as myocardial infarction, stroke, hypertension and traffic accidents. Nasal continuous positive airway pressure (nCPAP) ventilation is the gold standard in the treatment of obstructive sleep apnea syndrome (OSAS). Long-term compliance rates do not exceed more than 60 to $70 \%$. Other options like surgical procedure exist. But only one surgical procedure won't be successful in cases of moderate and severe OSA because one surgery will enlarge the airway only at one location. Alternative multi-level surgeries are of interest, combining procedures at the level of the base of tongue and the soft palate in order to stabilize the whole upper airway like the CPAP-ventilation. Several multi-level surgery concepts exist. Our multi-level surgery based on the hyoid suspension with the combination of a radiofrequency therapy of the tongue base brings out the effectiveness of this concept. With this concept we achieve a success rate of $57.6 \%$; this result situates us at the average level of the cited multi-level surgery studies. With this success rate this protocol can replace the CPAP mask especially in cases with CPAP intolerance or decline
\end{abstract}

Keywords: Obstructive sleep apnea syndrome (OSAS), multilevel surgery, hyoid suspension, CPAP

\section{Introduction}

In our modern competitive society, non-restorative sleep is acquiring an enhanced significance. The international classification of sleep disorders includes 80 different diagnoses of possible causes for non-restful sleep [1]. A subgroup with a comparatively high incidence rate is formed by the so-called sleep disordered breathing disorders (SDB). These are further divided into disorders with and without obstruction in the upper airway.

SDB with obstruction include primary snoring, upper airway resistance syndrome (UARS) and obstructive sleep apnea (OSA). Currently, these syndromes are regarded as different grades of severity of the same pathophysiological disorder [22]. Snoring is caused by vibrations of soft tissue in constricted segments of the upper airway. By definition, primary snoring is not accompanied by breathing impairment, and entails neither a disruption of sleep nor an increased daytime sleepiness. Primary snoring may lead to a social problem as a result of the nocturnal breathing sounds, but it is not essentially a disorder of the patient's physical health.

Yet in the case of OSA, an imbalance exists between forces dilating and occluding the pharynx during sleep. The muscle tone supporting the pharyngeal lumen is too low, and the inspiratory suction force as well as the pressure of the surrounding tissue, both narrow the pharynx, are to high $[29,27]$. This disorder occurs only during sleep due to a physiological loss of muscle tone of the pharyngeal muscles in this state. The effects are complete cessation of breathing (apneas) or reduced breathing phases (hypopneas). Both events trigger, if sustained long enough, an emergency situation for the body. The body reacts with a central arousal which disturbs the physiological sleep 
by a release of catecholamines. The latter lead via an increase of the tone of the sympathetic system to a strain upon the cardiovascular system.

In contrast to primary snoring, OSA has an adverse effect on the daytime life quality. Cardinal symptoms of OSA are intermittent snoring (94\%), daytime sleepiness $(78 \%)$ and diminished intellectual performance (58\%). Further symptoms are personality changes $(48 \%)$, impotence in men (48\%), morning headaches $(36 \%)$ and enuresis nocturna (30\%) [10].

Obstructive sleep apnea is a widespread disorder affecting up to $10.9 \%$ of the male and up to $6.3 \%$ of the female population $[16,40]$. It is associated with serious adverse consequences for afflicted individuals, such as myocardial infarction [15], stroke [5], hypertension [26] and traffic accidents [34].

The goal of any treatment consists in a complete elimination of all apneas, hypopneas, desaturations, arousals, snoring and other related symptoms in all body positions and all sleep stages. The standard therapy for obstructive sleep apnea is a night-time ventilation therapy with continuous positive airway pressure (CPAP) [33]. In almost all cases, CPAP ventilation enables the reduction of pathological respiratory events to a physiological level. This positive airway ventilation stabilizes the whole upper airway, which therefore is regarded as one unit (Figure 1). Unfortunately, the

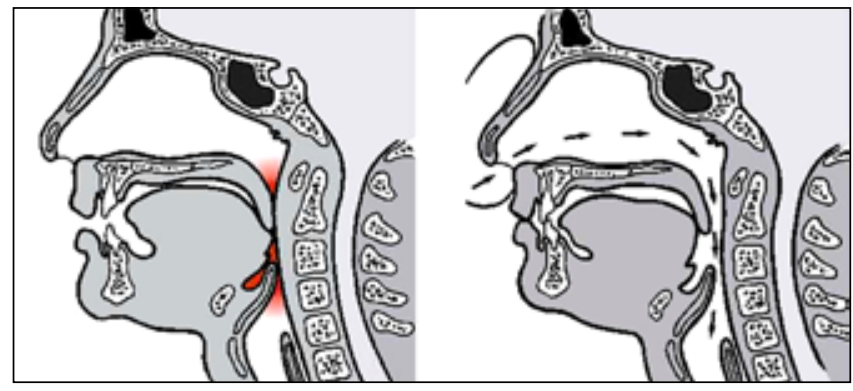

Figure 1: Method of pneumatic stenting of the upper airway with CPAP. Left) airway collapse. Right) stabilization with continuous positive airway pressure.
CPAP long-term compliance rate is assessed as below $70 \%$ [20]. Therefore surgical alternatives exist which stabilize the upper airway. Surgical interventions at one level of the upper airway (e.g. the soft palate) can not avoid obstructions located anywhere else in the airway. In order to be as successful as CPAP ventilation or to replace the CPAP mask various so-called multi-level surgery procedures exist.

A multi-level procedure for the surgical therapy of OSA was presented first in 1989 by Waite and colleagues [38]. The authors combined nasal surgery with a UPPP, tongue surgery, a genioglossus advancement, and a maxillomandibular advancement osteotomy (MMO). Basically, the classification of the upper airway into different levels of obstruction stems from Fujita [9], who distinguished between retropalatal, retrolingual, and combined retropalatal and retrolingual obstruction. On the basis of this distinction Riley et al. [30] defined the term and concept of multi-level surgery.

In the meantime, first studies have been published concerning virtually every possible combination of soft palate and tongue base procedures.

\section{Surgical Concepts}

For the sake of giving some structure to these data, we will distinguish in the following between minimally invasive concepts for mild OSA and more invasive concepts for moderate and severe OSA.

Effectiveness of Minimally-invasive multi-level surgery for mild to moderate OSA

Of the procedures employed, only the isolated RFQ therapy can be regarded as a minimally invasive technique. With an apnea-hypopnea-index (AHI) of 10/h to $20 / \mathrm{h}$ the patient suffer from a mild OSA; with an AHI of 20/h to 40/h the patient suffer from a moderate OSA. Table 1 presents two studies with only a radiofrequency (RFQ) -based multi-level surgery.

Table 1: Combined RFQ surgery for OSA. SP, soft palate; TB, tongue base; Tons, tonsills.

\begin{tabular}{|l|c|c|c|c|c|c|c|c|}
\hline \multicolumn{1}{|c|}{ Author } & N & $\begin{array}{c}\text { Application } \\
\text { sites }\end{array}$ & Device & $\begin{array}{c}\text { Follow-up } \\
\text { [months] }\end{array}$ & $\begin{array}{c}\text { Sessions / total } \\
\text { energy /lesions }\end{array}$ & $\begin{array}{c}\text { AHI } \\
\text { pre }\end{array}$ & $\begin{array}{c}\text { AHI } \\
\text { post }\end{array}$ & $\begin{array}{c}\text { Success } \\
\text { Rate [\%] }\end{array}$ \\
\hline Stuck et al. 2002 [32] & 18 & SP, TB & Somnus & 2 & $3 / 4300 \mathrm{~J} / 7$ & 25.3 & 16.7 & 38 \\
\hline Fischer et al. 2003 [7] & 15 & SP, TB, Tons & Somnus & 4.8 & $1 / 7750 \mathrm{~J} / 12$ & 32.6 & 22 & 20 \\
\hline all & 33 & & Somnus & 3.3 & & 28.6 & 19.1 & 30.3 \\
\hline
\end{tabular}

The table demostrates the limitation of RFQ surgery to cases of mild OSA with an AHI of maximally $20 / \mathrm{h}$. This trend is corroborated by the results of the currently single existing placebo-controlled study on this topic. Woodson et al. [39] treated 30 patients respectively either with CPAP, with combined RFQ at soft palate and tongue base, and with a sham operation. Unfortunately, the authors did not provide any raw data; therefore this study could not be included in table 1 . As expected, CPAP respiration was found to be superior to RFQ surgery, and RFQ in turn superior to the sham operation. Yet in regards to the subjective 
results, which were measured with various validated test instruments for the assessment of life quality, no differences were found in the comparison of CPAP with RFQ surgery.

The combined treatment of tongue base plus soft palate does not appear to significantly improve the results of an isolated tongue base treatment in respect to the AHI. In our clinical experience, the advantages of a combined treatment lie more in an additional effect upon the respiratory noises during sleep. We have recently been able to demonstrate [32] that the postoperative morbidity and complication rate after combined treatment and after isolated tongue base treatment are identical.
Effectiveness of multi-level surgery for moderate to severe $(A H I>40 / h) O S A$

On the level of the soft palate, invasive therapy concepts include either a UPPP or a uvulopalatal flap.

For the treatment of the hypopharyngeal obstruction different procedures have been recommended. Table 2 summarizes the existent data. In the case of a relevant clinical diagnosis several authors additionally perform nasal surgery. Recently, we were able to demonstrate that additional nasal surgery does not have a positive effect on the severity of the OSA $[35,36]$.

Table 2: Multi-level surgery for OSA. HS: hyoid suspension, GA: mandibular osteotomy with genioglossus advancement; MLP: midline partial glossectomy;

RFQ: radiofrequency of tongue base

\begin{tabular}{|c|c|c|c|c|c|c|c|}
\hline Author & $\mathbf{N}$ & $\begin{array}{c}\text { Technique } \\
\text { level } 1\end{array}$ & $\begin{array}{c}\text { Technique } \\
\text { level } 2 \\
\end{array}$ & $\begin{array}{c}\text { Follow-up } \\
\text { [months] }\end{array}$ & AHI pre & $\begin{array}{c}\text { AHI } \\
\text { post }\end{array}$ & $\begin{array}{l}\text { Success } \\
\text { Rate [\%] }\end{array}$ \\
\hline Djupesland et al. 1992 [4] & 19 & UPPP & MLP & 8.7 & 54 & 31 & 31.6 \\
\hline Riley et al. 1993 [30] & 223 & UPPP & GA HS & 9 & 48.3 & 9.5 & 60.1 \\
\hline Johnson et Chinn 1994 [17] & 9 & UPPP & $\mathrm{GA}$ & 39 & 58.7 & 14.5 & 77.8 \\
\hline Ramirez et Loube 1996 [28] & 12 & UPPP & GA HS & 6 & 49 & 23 & 41.7 \\
\hline Elasfour et al.1998 [6] & 18 & UPPP & MLP & $3-21$ & 65.0 & 29.2 & 44.4 \\
\hline Lee et al. 1999 [12] & 33 & UPPP & GA & $4-6$ & 55.2 & 21.7 & 66.7 \\
\hline Bettega et al. 2000 [2] & 44 & UPPP & GA HS & 6 & 45.2 & 42.8 & 22.7 \\
\hline Hsu et al. 2001 [14] & 13 & UPPP & GA HS & 12.6 & 52.8 & 15.6 & 76.9 \\
\hline Hendler et al. 2001 [11] & 33 & UPPP & $\mathrm{GA}$ & 6 & 60.2 & 28.8 & 45.5 \\
\hline Nelson 2001 [23] & 10 & UPPP & RFQ & 2 & 29.5 & 18.8 & 50.0 \\
\hline Vilaseca et al. 2002 [37] & 20 & UPPP & GA HS & 6 & 60.5 & 44.6 & 35.0 \\
\hline Neruntarat 2003 [25] & 32 & Flap & $\mathrm{HS}$ & 8.1 & 44.5 & 15.2 & 78.0 \\
\hline Neruntarat 2003 [24] & 49 & Flap & GA HS & 39.4 & 47.9 & 18.6 & 65.2 \\
\hline Friedman et al. 2003 [8] & 143 & UPPP & RFQ & no data & 43.9 & 28.1 & 41.0 \\
\hline Miller et al. 2004 [21] & 24 & UPPP & $\mathrm{GA}$ & 4.7 & 52.9 & 15.9 & 66.7 \\
\hline Dattilo et al. 2004 [3] & 37 & UPPP & GA HS & 1.5 & 38.7 & 16.2 & 70.3 \\
\hline Verse et al. 2004 [25] & 45 & Flap & RFQ, HS & 4.7 & 38.3 & 20.6 & 51.1 \\
\hline Hörmann et al. 2004 [13] & 66 & Flap & RFQ, HS & 3.4 & 38.9 & 19.3 & 57.6 \\
\hline all & 830 & & & $1-39$ & 47.1 & 20.6 & 53.9 \\
\hline
\end{tabular}

Altogether, data of 830 patients from retrospective studies and from prospective case control studies exist. The success rate according to Sher et al. [31] lies at almost $54 \%$. With the exception of the study by Nelson [23], the studies dealt with on average severe forms of OSA. We are of the opinion that a sufficient amount of data exist to validate the efficacy of multilevel surgery in the case of severe OSA.

Difficulties arise in attempting to evaluate the divergent concepts against each other. For the area of the soft palate, all study groups either perform the conventional UPPP or more rarely the uvulaflap, always including a tonsillectomy. We consider these techniques to be comparable. Therefore the concepts differ from one another in respect to the therapy of the hypopharyngeal constriction of the upper airway. Two study groups $[4,6]$ recommend in somewhat dated publications a partial resection of the tongue base. With $32 \%$ and $44 \%$ respectively the success rates lie below average.

Two further concepts $[8,23]$ solely employ the minimally invasive RFQ surgery at the tongue base. The retrospective analysis of Friedman et al. [8] achieves with $41 \%$ a relatively low success rate. Yet of interest in this study is the fact that a control group of patients, who only had received a UPPP, performed significantly worse. Nelson [23] presents with 50\% an average success rate, but treated patients with less severe OSA. The mean AHI in his series was $29.5 / \mathrm{h}$, compared to the mean value of all studies, which was $47.1 / \mathrm{h}$. Undoubtedly, of all the tongue base procedures presented here the RFQ has the lowest postop- 
erative morbidity and complication rate. But we infer from the data a tendency indicating that solely a RFQ at the tongue base, combined with the UPPP, is not in itself sufficient for properly treating a severe OSA with surgical means.

The majority of studies employs for the therapy of the hypopharyngeal constriction either the mandibular osteotomy with genioglossus advancement or the hyoid suspension or both. Currrently, the data does not provide information as to which combination is superior. It presumably depends more on the surgeon with which technique he or she achieves the best results. Initially, we followed the Stanford [30] concept. Yet after the mandibular osteotomy with genioglossus advancement several complications occured in our patient pool, such as infections of the oral floor with abscess formation and loosenings of the osteosynthesis; therefore, we have searched for alternatives with less complications. We believe to have found the solution for obstructions located hypopharnygeal. We perform the combination of RFQ of the tongue base and the hyoid suspension by Hörmann $[36,13]$. The hyoid suspension enlarges the upper airway in moving the hyoid bone anteriorly. The hyoid bone will be fixed to the thyroid cartilage in its new position [12] (Figure 2).

Table 3: Staged concepts of multi-level surgery for OSA. MMO: bimaxillary advancement; Non-Resp.: Non-Responder

\begin{tabular}{|l|r|r|r|r|r|r|}
\hline \multicolumn{1}{|c|}{ Author } & N stage 1 & $\begin{array}{c}\text { Non-Resp. } \\
\text { stage 1 }\end{array}$ & $\begin{array}{c}\text { N stage 2 } \\
\text { (MMO) }\end{array}$ & $\begin{array}{c}\text { Resp. stage 2 } \\
\text { (MMO) }\end{array}$ & $\begin{array}{c}\text { AHI pre } \\
\text { stage 1 }\end{array}$ & $\begin{array}{c}\text { AHI post } \\
\text { stage 2 }\end{array}$ \\
\hline Riley et al. 1993 [30] & 223 & $89(40 \%)$ & 24 & $23(97 \%)$ & 75.1 & 8.4 \\
\hline Lee et al. 1999 [19] & 33 & $11(33.3 \%)$ & 3 & $3(100 \%)$ & 74 & 5 \\
\hline Bettega et al. 2000 [2] & 44 & $34(77,3 \%)$ & 20 & $15(75 \%)$ & 59.3 & 11.1 \\
\hline Li et al. 2000 [18] & & & 19 & $18(94.7)$ & 63.6 & 8.1 \\
\hline Hendler et al. 2001 [11] & 33 & $18(54.5 \%)$ & 7 & $4(57.1 \%)$ & 90.1 & 16.5 \\
\hline all & 333 & $152(45.6 \%)$ & 73 & $63(86.3 \%)$ & 69.2 & 9.7 \\
\hline
\end{tabular}

The MMO is also in the context of multi-level surgery an eminently succesful treatment in regards to the severity level of the OSA. This is apparently also the case for morbidly obese patients. In a series of 23 obese sleep apneics with a mean BMI of $45 \mathrm{~kg} \mathrm{~m}^{-2}$ the Stanford two phase concept achieved a success rate of $82.6 \%$. In this series, the mean AHI fell from preoperatively $83 / \mathrm{h}$ to $10.6 / \mathrm{h}$ six months postoperatively. But it needs to be mentioned that the patients had also reduced their weight. The average BMI was postoperatively $43 \mathrm{~kg} \mathrm{~m}^{-2}$. The authors conclude from their data that counseling in regards to weight reduction and avoidance of weight gain will improve treatment outcomes.

It is striking that only a relatively small number of patients have actually chosen an MMO, as can be seen in two series $[19,30]$ : in both of the studies only $27 \%$
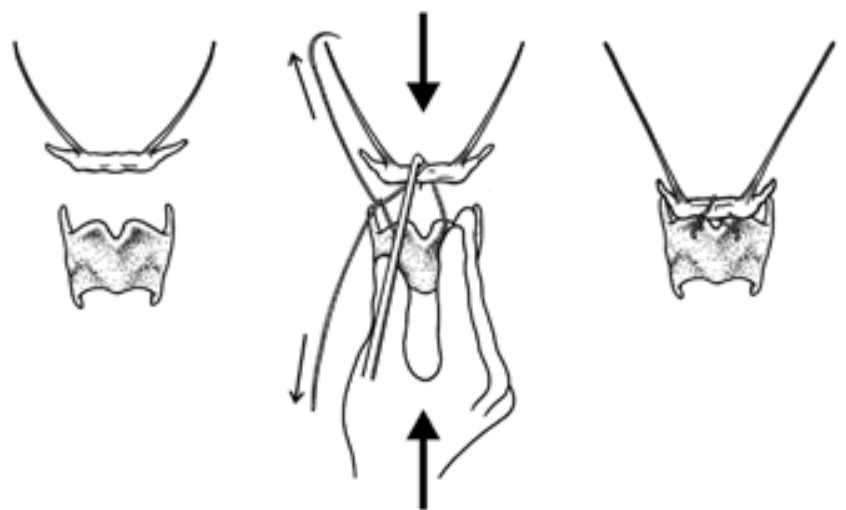

Figure 2: Hörmann's technique of hyoid suspension. Left) Preoperative situation. Center) Movement of the hyoid bone anteriorly and fixation to the thyroid cartilage with only one wire. Right) Situation after surgery.

In the context of this concept, tonsillectomy and hyoid suspension have shown themselves to be the most effective elements of our multi-level concept.

Obviously, the best success rates are found for staged concepts, which provide as a second, additional surgical stage a bimaxillary advancement in the case of the non-responders. This dividing up into 2 phases also goes back to the Stanford study group [30] and has gained acceptance in many places. The available data are presented in table 3 . of the candidates chose the option MMO. The reason for this remained unanswered in the studies. Apparently, due to the potential risks involved, MMO is not a surgical option for the majority of sleep apneics.

\section{Conclusion}

Minimally invasive multi-level surgery in the form of an isolated radiofrequency therapy is not effective in apneics with an AHI above 20/h. For these cases and cases with moderate and severe OSA we perform the combination of the uvula flap, the radiofrequency of the tongue base and the hyoid suspension by Hörmann. With this concept we achieve a success rate of $57.6 \%$ after Sher [31]; this result situates us at the average level of the cited multi-level surgery studies. With this success rate this protocol can replace the CPAP mask especially in cases with CPAP intolerance or decline. 


\section{References}

1. American Sleep Disorders Association: International Classification of Sleep Disorders (ICSD): Diagnostic and Coding Manual. Rochester, Minnesota: American Sleep Disorders Association 1997; 21- 24

2. Bettega G, Pepin JL, Veale D, Deschaux C, Raphael B, Levy P. Obstructive sleep apnea syndrome. Fifty-one consecutive patients treated by maxillofacial surgery. Am J Respir Crit Care Med 2000; 162: 641-649

3. Dattilo DJ, Drooger SA. Outcome assessment of patients undergoing maxillofacial procedures for the treatment of sleep apnea: comparison of subjective and objective results. J Oral Maxillofac Surg 2004; 62: 164-168

4. Djupesland G, Schrader H, Lyberg T, Refsum H, Lilleas F, Godtlibsen OB. Palatopharyngoglossoplasty in the treatment of patients with obstructive sleep apnea syndrome. Acta Otolaryngol 1992; Suppl 492: 50-54

5. Dyken ME, Sommers VK, Yamada T, Ren ZY, Zimmerman MB. Investigating the relationship between stroke and obstructive sleep apnea. Stroke 1996; 27: 401-407

6. Elasfour A, Miyazaki S, Itasaka Y, Yamakawa K, Ishikawa K, Togawa $\mathrm{K}$. Evaluation of uvulopalatopharyngoplasty in treatment of obstructive sleep apnea syndrome. Acta Otolaryngol 1998; Suppl 537; 52-56

7. Fischer Y, Khan M, Mann WJ. Multilevel temperature-controlled radiofrequency therapy of soft palate, base of tongue, and tonsils in adults with obstructive sleep apnea. Laryngoscope 2003; 113: 1786-1791

8. Friedman M, Ibrahim H, Lee G, Joseph NJ. Combined uvulopalatopha ryngolplasty and radiofrequency tongue base reduction for treatment of obstructive sleep apnea/hypopnea syndrome. Otolaryngol Head Neck Surg 2003; 129: 611-621

9. Fujita S.Obstructive sleep apnea syndrome: pathophysiology, upper airway evaluation and surgical treatment. Ear Nose Throat J 1993; 72: $67-72$

10. Guilleminault C, van den Hoed J, Mitler MM. In: Guilleminault C, Dement WC: Sleep apnea syndromes. Alan R. Liss Inc, New York; 1978: p1-12

11. Hendler BH, Costello BJ, Silverstein K, Yen D, Goldberg A. A protocol for uvulopalatoplasty, mortised genioplasty, and maxillomandibular advancement in patients with obstructive sleep apnea: an analysis of 40 cases. J Oral Maxillofac Surg 2001; 59: 892-897

12. Hörmann K, Baisch A. How I do it: The Hyoid Suspension. Laryngoscope 2004; 114: 1677-9

13. Hörmann K, Maurer JT, Baisch A. Snoring / Sleep Apnea - The Success of surgery [in German]. HNO 2004; 52: 807-13

14. Hsu PP, Brett RH. Multiple level pharyngeal surgery for obstructive sleep apnoea. Singapore Med J 2001; 42: 160-164

15. Hung J, Whitford EG, Parsons RW, Hillman DR. Association of sleep apnoea with myocardial infarction in men. Lancet 1990; 336: 261-264

16. Jennum P, Hein HO, Suadicani P, Gyntelberg F. Cardiovascular risk factors in snorers. A cross sectional study of 3323 men aged 54 to 74 years: the Copenhagen Mal Study. Chest 1992; 102: 1371-1376

17. Johnson NT, Chinn J. Uvulopalatopharyngoplasty and inferior sagittal mandibular osteotomy with genioglossus advancement for treatment of obstructive sleep apnea. Chest 1994; 105: 278-283

18. Li KK, Riley RW, Powell NB, Guilleminault C. Maxillomandibular advancement for persistent obstructive sleep apnea after phase I surgery in patients without maxillomandibular deficiency. Laryngoscope 2000; 110: $1684-1688$

19. Lee NR, Givens CD, Wilson J, Robins RB. Staged surgical treatment of obstrcutive sleep apnea syndrome: a review of 35 patients. J Oral Maxillofac Surg 1999; 57: 382-385

20. McArdle N, Dervereux G, Heidarnejad H, Engleman HM, Mackay TW, Douglas NJ. Long-term use of CPAP therapy for sleep apnea / hypopnea syndrome. Am J Respir Crit Care Med 1999; 159: 1108-1114
21. Miller FR, Watson D, Boseley M. The role of genial bone advancement trephine system in conjunction with uvulopalatopharyngoplasty in the multilevel management of obstructive sleep apnea. Otolaryngol Head Neck Surg 2004; 130: 73-79

22. Moore K. Site specific versus diffuse treatment / presenting severity of obstructive sleep apnea. Sleep Breath 2000; 4: 145-146

23. Nelson LM. Combined temperature-controlled radiofrequency tongue reduction and UPPP in apnea surgery. Ear Nose Throat J 2001; 640-644

24. Neruntarat C. Genioglossus advancement and hyoid myotomy: shortterm and long-term results. J Laryngol Otol 2003; 117: 482-486

25. Neruntarat C. Hyoid myotomy with suspension under local anesthesia for obstructive sleep apnea syndrome. Eur Arch Otorhinolaryngol 2003; 260: 286-290

26. Peppard P, Young T, Palta M, Skatrud J. Prospective study of the association between sleep disordered breathing and hypertension. $\mathrm{N}$ Engl J Med 2000; 342: 1378-1384

27. Phillipson EA. Control of breathing during sleep. Am Rev Respir Dis 1978; 118: 909-939

28. Ramirez SG, Loube DI. Inferior sagittal osteotomy with hyoid bone suspension for obese patients with sleep apnea. Arch Otolaryngol Head Neck Surg 1996; 122: 953-957

29. Remmers JE, de Groot WJ, Sauerland EK, Anch AM. Pathogenesis of the upper airway occlusion during sleep. J Appl Physiol 1978; 44: 931-938

30. Riley RW, Powell NB, Guilleminault C. Obstructive sleep apnea syndrome: A review of 306 consecutively treated surgical patients. Otolaryngol Head Neck Surg 1993; 108: 117-125

31. Sher AE, Schechtman KB, Piccirillo JF. The efficacy of surgical modifications of the upper airway in adults with obstructive sleep apnea syndrome. Sleep 1996; 19: 156-177

32. Stuck BA, Starzak K, Verse T, Hörmann K, Maurer JT. Combined radiofrequency volumetric tissue reduction of tongue base and soft palate - morbidity and complications [in German]. Somnologie 2002; 6: $19-25$

33. Sullivan CE, Issa FG, Berthon-Jones M, Eves L. Reversal of obstructive sleep apnoea by continuous positive airway pressure applied through the nares. Lancet 1981; 1: 862-865

34. Teran-Santos J, Jimenez-Gomez A, Cordero-Guevara J. The association between sleep apnea and the risk of traffic accidents. Cooperative Group Burgos-Santander. N Engl J Med 1999; 340: 847-851

35. Verse T, Baisch A, Hörmann K. Multi-level surgery for obstructive sleep apnea. Preliminary objective results [in German]. LaryngoRhino-Otol 2004; 83: 516-522

36. Verse T, Baisch A, Maurer JT, Stuck BA, Hörmann K. Multi-level surgery for obstructive sleep apnea. Otolaryngol Head Neck Surg; manuscript submitted

37. Vilaseca I, Morello A, Montserrat JM, Santamaria J, Iranzo A. Usefulness of uvulopalatopharyngoplasty with genioglossus and hyoid advancement in the treatment of obstructive sleep apnea. Arch Otolaryngol Head Neck Surg 2002; 128: 435-440

38. Waite PD, Wooten V, Lachner JH, Guyette RF. Maxillomandibular advancement surgery in 23 patients with obstructive sleep apnea syndrome. J Oral Maxillofac Surg 1989; 47: 1256-1261

39. Woodson BT, Steward DL, Weaver EM, Javaheri S. A randomized trial of temperature-controlled radiofrequency, continuous positive airway pressure, and placebo for obstructive sleep apnea syndrome. Otolaryngol Head Neck Surg 2003; 128: 848-861

40. Young T, Palat M, Dempsey J, Skatrud J, Weber S, Badr S. The occurrence of sleep-disordered breathing among middle-aged adults. $\mathrm{N}$ Engl J Med 1993; 328: 1230-1235

\section{Correspondence:}

Prof. Dr. med. Karl Hörmann

University Hospital Mannheim

Department of Otolaryngology, Head and Neck Surgery

D-68135 Mannheim, Germany

phone: +49 (621) 383-3965; fax: +49 (621) 383-3827

E-mail: karl.hoermann@hno.ma.uni-heidelberg.de 